\title{
Formación docente en E1 Salvador: Implicaciones en la educación salvadoreña
}

\author{
Teacher training in El Salvador: implications in \\ salvadoran education
}

Óscar Luna

Director de la revista Disruptiva del Instituto de Ciencia, Tecnología e Innovación de la Universidad Francisco Gavidia (ICTI-UFG)

e.oluna@ufg.edu.sv

Fecha de recepción: 13 de marzo de 2019 Fecha aprobación: 28 de noviembre 2019 DOI: 10.5377/ryr.v50i50.9091

\section{RESUMEN}

El presente artículo tiene como objetivo establecer un diálogo sobre las distintas visiones acerca de la formación docente en El Salvador y sus implicaciones en la educación. Para ello se decidió entrevistar a diferentes personalidades que conocen del tema, ya sea por su actual estatus de funcionario público o por ser parte de procesos de formación, o por ser docentes, que permitirá, a juicio de los autores, ampliar el debate y así dar distintas aristas al tema en cuestión. Para comenzar este artículo,se presentará, a grosso modo, el estado actual de la formación docente en el país. Después de exponer este marco legal/histórico se procederá a presentar las entrevistas realizadas a los funcionarios seleccionados, a las docentes y con el formador de docentes. Las entrevistas fueron realizadas separadamente durante el año 2018 y 2019 siendo grabadas y textualizadas. Por último, luego de las entrevistas se realiza un pequeño análisis de los aportes de los entrevistados. Se espera con la publicación del artículo incentivar al debate crítico sobre la formación docente.

Palabras clave: Educación, Formación docente, El Salvador 


\section{ABSTRACT}

The aim of this article is to establish a dialogue on the different visions of teacher education in El Salvador and its implications for education. For this, it was decided to interview different personalities who know about the issue, either because of their current status as a public official or because they are part of training processes, or because they are teachers, which will allow, in the opinion of the authors, to broaden the debate and thus give different edges to the subject in question. To begin this article, we will present, roughly, the current state of teacher training in the country. After this legal / historical framework, the interviews conducted with the selected officials, the teachers and the teacher educator will be presented. The interviews were conducted separately during the year 2018 and 2019 being recorded and textualized. Finally, after the interviews a small analysis of the contributions of the interviewees is made. It is expected with the publication of the article to encourage critical debate on teacher training.

Keywords: Education, teacher training, El Salvador.

\section{Introducción}

El presente documento busca iniciar una discusión y diálogo sobre la formación docente en El Salvador y sus implicaciones en la educación salvadoreña. Para la consecución de este objetivo, se realiza una pequeña contextualización sobre el estado actual de la formación de los educadores desde el aspecto legal e histórico, luego se presenta la opinión al respecto de dos funcionarios que trabajan el tema con el MINED -en el momento de realizar estas entrevistas, el ministerio tenía apellidos que le duraron muy pocos meses: el Ministro de Educación, Ciencia y Tecnología-: Carlos Canjura y el coordinador del Instituto Nacional de Formación Docente: Carlos Rodríguez. A estas voces institucionales se decidió unir, también, las voces de docentes y docentes formadores: Rosario Melgar de Varela y Consuelo Cabezas de Linqui, ambas fueron docentes formadas en las extintas escuelas normales -luego fueron formadoras y Roberto Salomón es una voz autorizada en materia de Educación Artística.

Sin más que agregar, un pequeño marco histórico/legal de la formación docente en El Salvador.

\section{Antecedentes}

El sistema salvadoreño de formación docente en vigencia surge de la reforma educativa de 1995, impulsada por la administración de la entonces ministra de Educación: Cecilia Gallardo de Cano. Esta reforma educativa incluyó un cambio del sistema de formación docente universitario que es el encargado de formar a los docentes desde el cierre de la Ciudad Normal Alberto Masferrer en 1980. Tuvo que pasar casi dos décadas para que el Estado regulara a las universidades en lo referente a la formación de profesores.

Esta reforma del sistema de formación docente se ejecutó plenamente a partir del año 1998 e incluyó varias modificaciones importantes, entre ellas la primera y principal fue que el Gobierno Central retomaba el control exclusivo en la formación de los profesores. Esto en la práctica significó que el entonces MINED podía definir totalmente los planes de estudio de las carreras que habilitan a la formación de los docentes, solicitar y dar un seguimiento a las universidades que ofertan las carreras y establecer criterios de ingreso, permanencia y egreso de los aspirantes a la carrera magisterial y de permiso para el ejercicio de la docencia en el sistema educativo 
público y privado gracias al nuevo marco legal establecido en la "Ley de la Carrera Docente" y a la "Ley General de Educación" aprobadas en 1996, marzo y diciembre respectivamente. Sin embargo, luego de más veinte años de aprobadas estas leyes, existen aún vacíos en fondo y forma sobre cómo deberíamos formar a los docentes en el país, ¿cuál debe ser el enfoque de la formación de los docentes?, ¿cuáles fueron las consecuencias del período de "desregulación" entre los años 1980 y 1995?, ¿qué aspectos legales deberían modificarse?, ¿qué se puede hacer y no hacer?, ¿qué referentes deben direccionar las políticas de formación docente?, ¿y la formación continua?, ¿el papel de las universidades y los docentes en servicio? Estas y otras preguntas fueron dialogadas con los expertos seleccionados.

A continuación entramos en el diálogo con el Ministro de Educación, Ciencia y Tecnología, Carlos Canjura, el coordinador del Instituto Nacional de Formación Docente, Carlos Rodríguez; las docentes normalistas Rosario M. de Varela y Consuelo C. de Linqui y con Roberto Salomón, experto en educación artística. En negrita se resaltan a las intervenciones del entrevistador.

\section{Formación docente en El Salvador: hablan los expertos}

\section{Carlos Canjura}

Fue el Ministro de Educación del segundo Gobierno del partido de izquierda Frente Farabundo Martí para la Liberación Nacional (2014 - 2019). A poco más de seis meses del cambio de Gobierno, Carlos Canjura habló con la revista Disruptiva sobre educación, la rama que él ha dirigido los últimos cinco años. Y decidimos iniciar no por la parte económica del tema, sino, por la parte que más debería importarnos: qué enseñamos en nuestro sistema educativo.

\section{¿En El Salvador se enseña lo que debería enseñarse?}

Por un lado hay que preguntarse si lo que es toda esta avalancha científica y tecnológica que está invadiendo el mundo de ahora..., la escuela es capaz de absorberla. Ahí hay que reflexionar un tanto sobre los modelos educativos que hemos venido teniendo. Y esto tiene que ver con todos los niveles educativos. Quizá el que más pronto debe absorber esos cambios que se dan es el universitario y desafortunadamente este se ha movido poco. Si vemos el concierto de universidades en el sistema nuestro, lo que se enseña, sigue siendo muy clásico. Preguntémonos cuántas carreras están asociadas a las novedades que tienen la tecnología.

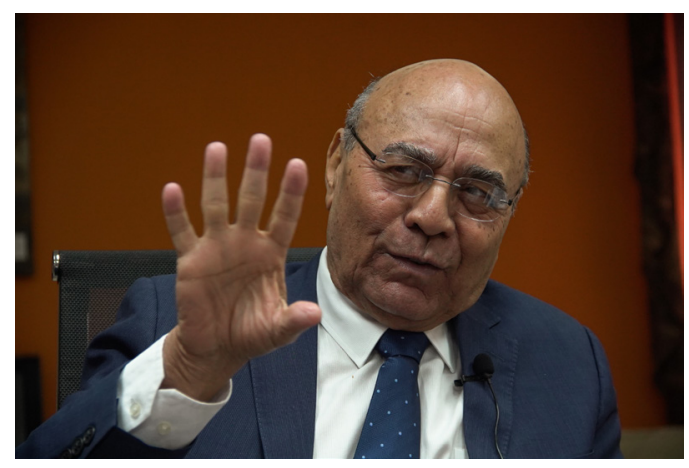

Imagen $n^{\circ}$ 1. Carlos Canjura, exministro de Educación, Ciencia y Tecnología. Fotos: Raúl E. Benítez, periodista multimedia. 
Sí, las universidades son los agentes de cambio y necesitan una sacudida. Necesitan ampliar su oferta. Pero, ¿los jóvenes vendrían preparados de las escuelas para hacerle frente a nuevas carreras.

Estamos hablando del primer nivel que debe moverse para que se dinamice el sistema educativo, porque la generación de conocimientos si bien es cierto no podemos delegársela de manera exclusiva al nivel universitario, es el nivel privilegiado de apropiación y de generación de conocimiento, para dinamizar cualquier campo, ya sea en la economía, en la agricultura, en la tecnología, en la matemática, lo que sea.

Carlos Canjura hace hincapié en uno de los problemas que tiene el país desde hace años: muchísimos graduados de pocas carreras.

Nosotros tenemos decenas de miles en ciertas carreras. Decenas de miles en donde prácticamente la posibilidad de un empleo en esa especialidad se ha vuelto ya muy rara. Es muy poco probable que nuestros jóvenes graduados encuentren empleos en ciertas zonas donde tenemos excedentes escandalosos. Por otro lado tenemos producciones limitadas en campos muy importantes para atender lo que son las necesidades nacionales. Nuestra vocación en las diferentes regiones del país no está claramente expresa en el nivel universitario. Por ejemplo, lo que ya se ha comentado mucho, ¿Cuál es la oferta universitaria respecto al mar? Pues, no tenemos. Y hay un esfuerzo que se hizo en la Universidad de El Salvador a principios de este milenio y por ahí ha estado con mucha dificultades, porque también hay ciertos niveles de incomprensión de la importancia que tienen estas áreas de conocimiento y que a lo mejor nos permitiría generar mejores condiciones para lograr la prosperidad en nuestro pueblo en la medida en que seamos más capaces de conocer lo que tenemos como país.

\section{En 2018, el Ministerio de Educación cambió} su nombre y se puso dos apellidos: Ministerio de Educación, Ciencia y Tecnología. ¿Cómo vamos a hacer operativos estos apellidos si todavía hay escuelas que no tienen luz?

No es tan así. Yo creo que hay que entender que las cosas tienen ciertas dinámicas y que no todo se puede resolver simultáneamente. Yo sí creo que nosotros tenemos tremendo déficit histórico con el sistema educativo y si no se atienden esos problemas históricos, la prosperidad jamás va a llegar.

Tenemos que tener mayores capacidades para producir, mayores capacidades para hacer de manera eficiente el uso de los recursos y eso supone sin duda el paso por ciencia y tecnología. Trabajar en esa dirección y trabajar en la recuperación de estos espacios, yo diría de dignificación de lo que es el sistema escolar no son uno detrás del otro. Sino que tienen que ser simultáneos, porque la posibilidad real de atender esto supone generación de riqueza para poder atender ese problema. Los niveles educativos en sus sistemas primarios, no creo que el problema central de los niveles educativos, en sus sistemas primarios, sea lo que se enseña; ya que ahí hay dominios elementales de Lenguaje, dominios elementales de Matemáticas, por el que debe pasar todo joven, no importa el nivel sofisticado que aspire más adelante. Es en la construcción de las capacidades fundamentales de la estructura, de las operaciones matemáticas básicas, de sus primeros contactos con la ciencia, que tenemos que revisar cómo es que se está haciendo. No es lo mismo que le cuenten a un niño 
acerca de la célula a que la vea en un microscopio. Cuando un niño se enfrenta a esa maravilla es posible que se inspire. Es muy difícil que con una cosita que se le dibuja en la pizarra se logre ese nivel de motivación.

\section{El camino a enseñar Ciencia y Tecnología es un gran paso. Pero antes de hablar de eso y de microscopios en las aulas hay que hablar de maestros. Estos, según el Ministro, son los tres grandes errores históricos que ha cometido el país con los docentes.}

Sin duda los sistemas educativos se mueven por los maestros. Ahí yo estoy absolutamente convencido de eso. Y debemos reconocer que históricamente hemos cometido demasiados, errores. El error por ejemplo de cerrar la Universidad Pública en 1972. Cerrar por más de un año, cuando era una universidad que tenía una planta académica construida y que no tuvo esa gente... a la que no la exiliaron, porque exiliaron a muchos, emigraron porque ya no encontraron aquí el espacio para seguir desarrollando su academia. Eso destruye. A mi criterio, fue una de de las más groseras decisiones históricas, en la historia del país. Y afectó al sistema educativo. Otro error fue . Está el otro cierre de 1980, otra grosería, otra decisión de lo más nefasto que hubo, cerraron el campus universitario por cuatro años y la universidad pública tuvo que hacer un ejercicio heroico de vivir en muchas sedes dispersas en condiciones muy, muy incómodas, durante cuatro años. Y que no solo desanimó todo lo que se había hecho antes del 72 sino que lo coronó como una drástica caída de la moral académica, porque cuando el espacio donde tenía que estar el cuerpo académico no existía, no existía más que aula, una vez dada su clase la gente debía salir de ahí porque no había donde estar. No solo deteriora la aspiración académica sino que deteriora el nivel de compromiso que tiene con la construcción de las nuevas generaciones y su compromiso con la generación de conocimiento, porque cuando se percata que le tratan de esa manera, se termina preguntando si vale la pena el esfuerzo que hace [risas]. Todo esto se corona con el cierre de la Escuela Normal para entregárselo a un batallón. Esa es otra grosería que refleja el poco peso que le concedíamos a la educación. A lo mejor la guerra exigía tomar decisiones pero caerle al sistema educativo para resolver un problema militar me parece que es una decisión triste.

\section{¿Cómo se construye un buen maestro?}

La construcción de maestros no puede verse como se ha estado viendo históricamente en el país. La construcción de maestros requiere el mayor cuido de parte del estado en su conjunto, porque a los maestros se les asigna una tarea de primer nivel, es construir el ciudadano del futuro, es desarrollar en él las altas responsabilidades ciudadanas y construir en él las altas capacidades productivas. Y aquí puede ser que nos resultaba indiferente quién jugaba el papel de educador. Lo producimos sin mayor cuido a veces sin tan siquiera de la misma especialidad. Porque sin duda el que no sabe una especialidad es muy difícil que provoque, que entusiasme, que enamore a los jóvenes a que busquen ese campo. La única forma que un niño, un joven pueda entusiasmarse es cuando encuentra a alguien que ama lo que está haciendo. Si no gusta de lo que enseña, ese disgusto se lo transmite, se lo diga o no se lo diga. pareciera que en nuestro sistema educativo la misma legislación le daba la posibilidad de ser maestro sin tener especialidad; es decir, ejercer el papel de maestro 
de química sin jamás haber recibido química; eso refleja un nivel casi de desprecio de lo que es el conocimiento. Es decir, de ejercer el papel de maestro de química sin jamás haber recibido química. Eso refleja un nivel casi de desprecio de lo que es el conocimiento.

\section{¿La solución pasa por seguir capacitando maestros o por empezar todo de nuevo?}

Los sistemas educativos no pueden decir: "Cerremos todo y empecemos desde cero" pero una cosa sí es clara, solo construir capacidades para atender las diversas necesidades que requiere el sistema de educación nacional. Solo construir, parémonos en eso. Usted necesita construir maestros de matemáticas, de química, de biología, de física, computación, historia, geografía, economía, antropología, tecnologías, inglés, primera infancia, todo lo que significa la construcción del cerebro y lo tiene que construir para los diferentes niveles educativos. Entonces vamos a ver cuánto construimos de maestros de música, cuántos de teatro, cuántos de danza, cuántos de educación física, pregúntense lo que estamos construyendo en el país en esas áreas. Entonces le invito a que revise lo que se produce en el sistema universitario, cuántos profesores, y contraste lo que le acabo de decir con oferta. $\mathrm{Y}$ ahí vamos a ver por qué nuestro sistema educativo está lejos de ser integral. Y lo integral tiene que ver con la formación de nuestros ciudadanos. Tenga ese nivel de integralidad. Pero además tiene la importancia de que nadie sabe a priori a dónde está el potencial, a dónde está el talento de nuestro niño. Y está claro que si tiene talento para el teatro y nunca tiene la oportunidad de hacer teatro en su escuela nunca se dará cuenta que él era talentoso para ello. Si él tiene talento para la música no se va a percatar si no pasa por música. Si nunca pasa por una buena matemática nunca se va a percatar si él era talentoso para eso. Y bueno las necesidades del sistema educativo pasan por asegurar a nuestra a niñez se le oferta toda esa gama de posibilidad para que él se descubra. No es cuestión de aprobarlo o desaprobarlos, sino encontrar dónde es que él tiene su máximo potencial, su máximo gusto. $Y$ ahí la importancia del maestro, porque el maestro es el que provoca, el que entusiasma, el que motiva a que se vaya por cierta ruta.

No podemos cambiar todo de nuevo pero estamos cambiando cosas para mejorarlas.

\section{¿Estos frutos los veremos a corto o a mediano plazo?}

Ningún atajo en educación es sensato. La educación no tiene atajos. Aquí hay que tener claridad de que es lo mismo que pasa con los hijos. ¿Cómo se construye un hijo? ¿Atendiéndolo en enero y después olvidándolo los otros meses del año?, ¿ $\mathrm{O}$ atendiéndolo un año y los otros años no? No, un hijo se construye en el día a día. Eso es el sistema educativo. La construcción de ciudadanos tiene que ver con todos los años que permanece en el sistema educativo, no es cuestión de un ratito. $\mathrm{Y}$ de ahí que nuestros sistema de evaluación deben estar íntimamente relacionados a los grandes propósitos que debe tener nuestro sistema educativo. El más grande propósito de un sistema educativo, cualquiera que sea, es construir el ciudadano que se aspira en la sociedad. Entonces hay que preguntarse, ¿cómo se evalúa eso? ¿Y quién es el responsable de hacer eso? Y aquí se ha confundido lo que yo he dicho respecto a la a la Prueba de Aprendizaje y Aptitudes para Egresados de Educación Media (PAES). La PAES es una prueba insuficiente 
para decir si es un buen ciudadano o no. Yo no estoy seguro de si un estudiante que tiene cinco en la PAES es o no un buen ciudadano.

No puedo decirlo. Y tampoco porque la nota es buena en la PAES puedo decir que es un buen ciudadano. No es al final una prueba que sea certera respecto a lo que estamos hablando. Sin embargo es un buen parámetro, un buen parámetro en la medida que obviamente si no tiene estas capacidades construidas va a ser difícil que alcance buenos niveles de formación. Si nosotros confiáramos en la evaluación cotidiana del maestro y que el maestro diera fe: «Mire, este muchacho vale la pena que pase al siguiente grado con esta, esta, y esta valoración en cuanto a su comportamiento como ciudadano del futuro y en cuanto a las capacidades que va construyendo». Como lo he dicho muchas veces, ¿qué es lo que ocurre si un maestro prueba lo que un niño sabe de matemáticas en noveno grado y lo prueba haciendo un ejercicio cualquiera? Bueno, si acaso le pregunta algún cálculo de área, si le pregunta cuál es el área del rectángulo de seis por ocho y entonces el cipote le dice 48 y cree que sabe. No, el problema es que yo debo ponerlo en una condición en donde todo ese conocimiento que tiene acumulado lo puede utilizar en un problema complejo con el que seguramente él se va a enfrentar en su vida. Si yo le digo aquí en este salón que vamos a cambiar este ladrillo y vamos a poner ladrillo de 15 por 15 calcúleme todo esto, ese es un problema que tiene un ciudadano. Ese es un problema que debe resolver un cipote de noveno grado y si no lo puede resolver es que no estamos haciendo lo que debemos hacer en el sistema educativo, porque no se trata de que me calcule el área de un rectángulo de seis por ocho, se trata de que enfrente problemas de su vida y que seguramente lo va a necesitar. Si un estudiante no sabe calcularme el número de yardas que lleva esta sala en qué estamos, ¿verdad? Si no puede estimar cuántas yardas se requieren para hacer un pantalón de un niño de 12 años de cierta estatura. Estas son las cosas para las que se enseñan matemáticas, para enfrentar ese tipo de problemas. Eso tenemos que preguntarnos, si lo estamos haciendo así en el sistema educativo. Y si no lo estamos haciendo así, entonces, ¿qué debemos hacer para que nuestros maestros asuman esa tarea de evaluar con esa otra mirada de sus capacidades productivas en el desarrollo en el sistema educativo?

\section{Nuestro programa de estudio o nuestra currícula ya tiene 10 años. ¿Ya es tiempo de cambiarla o no?}

Aquí hemos creído que currícula es un documento y para mí currícula es todo un proyecto social. La currícula es el proyecto educativo de la nación. Y como proyecto que es lo primero que debemos hacer es que los actores fundamentales estén claros de la currícula. Uno no puede cambiar currícula simplemente cambiando documento. Uno cambia currículos cuando nuestros maestros y maestras cambian. Si ellos no cambian, aunque usted cambie el currículo, como documento, las cosas no cambian. Y esa ha sido la historia de nuestro país. Ponen nuevos programas con profesores que no han estado en un proceso donde se asimile de manera sensata los cambios que se han propuesto en ese currículo. Nosotros hemos venido trabajando en la dirección justamente contraria. Nos hemos estado ocupando de los maestros del sistema. Y hoy nos estamos ocupando de los formadores de maestros en el sistema universitario. Una de las tareas fundamentales que tiene el Instituto 
Nacional de Formación Docente es justamente ocuparse de generar espacios a los formadores de maestros para que ellos mismos crezcan en tanto educadores en sus diferentes especialidades. Claro, que estamos poniendo en un primer momento porque el INFOD, el Instituto Nacional de Formación Docente se inició el 22 de junio de este año pero ya ha hecho bastante. $\mathrm{El}$ coordinador que hemos puesto es un joven que tiene muy buena dinámica, muy talentoso que yo estoy seguro que va a ser buena semilla esa del instituto. Ocuparse de los formadores de maestros es también un tema fundamental. No puedes estar creyendo que la tarea es solo atender a los maestros que están en servicio. Tenemos que ir a ver que se construyan bien los maestros del futuro. Y la mejor manera de asegurar que eso es posible, es mejorando las condiciones de los formadores de maestros. Porque tiene que moverse todo el sistema y como digo el primer nivel que hay que afectar, porque la generación de conocimiento que debe penetrar todo el sistema es el nivel universitario.

Las currículas sí deben cambiarse pero nosotros estamos intentando que nuestros especialistas, como ya tenemos generados un poco más de 2 mil en diferentes especialidades, les estamos dando la tarea de que ya discutamos entonces cuál es el currículo. Porque sale muy fácil decir, currículo, porque sale muy fácil decir: "Yo contrato un especialista, un curriculista y ¡chaz!". Esa es la historia del país y no ha habido una verdadera transformación de los maestros que permita que ese nuevo currículo tenga vida en el aula, tenga vida en la escuela y la única manera en que puede tener vida es si está encarnado en los maestros. Ese es el tema. El exministro tiene claro lo que funciona $\mathrm{y}$ lo que no funciona en este sistema educativo.
Entonces, ¿por qué no se cambia? No. Nuestra administración si usted revisa los hechos, nosotros año con año hemos atendido 30 mil maestros. Año con año, insistiendo en esto y no hemos convocado para una preparación de ocho horas, no. Los hemos invitado a participar en proceso de formación de 960 horas. Conscientes de que ahí está la mejor solución al problema. Nosotros tenemos todas las especialidades del sistema. Incluso uno que nunca hemos tratado, el tema de educación inicial. La atención de cero a tres años. Nosotros estamos trabajando en la construcción de 420 especialistas en ese tema porque creemos que ese nivel se destaque en el país como un nivel donde nosotros podemos jugar nuestra mejor jugada para las futuras generaciones. Porque ese periodo de construcción del cerebro, ese periodo donde el niño puede recibir la alimentación adecuada, la nutrición adecuada, el cuido de salud adecuado, los estímulos para sus capacidades cognitivas, sus estímulos para sus capacidades psicomotoras, sus estímulos para generar buenos sentimientos, porque al final estos se construyen igual en el cerebro y por medio de las relaciones con su entorno, de esas en las que intervienen incluso la mirada de sus madres cuando amamanta a sus hijos. Eso es importante, si no le ponemos atención a ese periodo, el cerebro puede tener muchas complicaciones, posteriormente le condena el resto de su vida. Así que ponerle atención a ese periodo de construcción inicial del cerebro es de primer orden y tenemos que estar claros como sociedad que aquí la participación de Salud, Educación, municipales y la familia es muy importante porque necesitamos hacerle entender a las familias que los buenos sentimientos se construyen desde los primeros días de vida y no a los 15 años . En este sentido, si prestamos atención a estos aspectos tendremos un niño que llegará a 
su primer grado con otras capacidades cognitivas y en donde ya no tendremos que trabajar de manera desventajosa para desarrollarlas.

Es claro que este exministro y por ende su ministerio apostaban a la especialización de los maestros y por eso se creó el INFOD, el Instituto Nacional de Formación Docente, coordinado por el filósofo Carlos Rodríguez. Es por ello que se decidió entrevistarlo. A continuación se desarrolla la entrevista con él.

\section{Carlos Rodríguez}

Es licenciado en Filosofía, coordinador del Centro Nacional de Investigaciones en Ciencias Sociales y Humanidades (CENICSH), miembro del comité editorial del Ministerio de Educación y es un investigador más del Programa de Investigación Educativa del CENICSH. El aporte más importante que tuvo la oportunidad de hacer debió venir del INFOD, ya que era el encargado de formar a los formadores, uno de los pasos que, según el mismo ministro, Carlos Canjura, era primordial para empezar a mover la currícula y el sistema educativo en general.

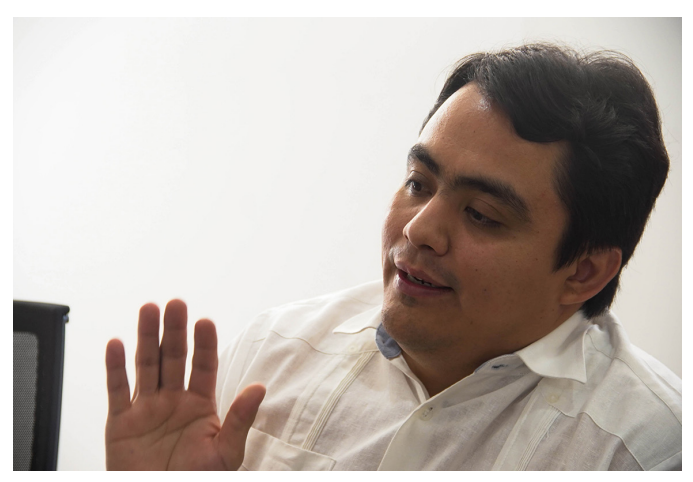

Imagen $n^{\circ}$ 2. Carlos Rodríguez Rivas, coordinador del Instituto Nacional de Formación Docente. Fotos: Raúl E. Benítez, periodista multimedia.
E1 INFOD y Carlos tienen un enorme reto, seguir capacitando maestros cuando ya existen más de 40 mil profesionales en pedagogía que están esperando ingresar al sistema educativo.

\section{Primero, Carlos nos explica qué es el INFOD}

Bueno, quizá un poco contextualizar. Esta iniciativa del Instituto Nacional de Formación Docente no podemos como Ministerio reclamar su originalidad porque la creación de una instancia pública especializada en la formación de docentes que retome las deudas y los desafíos que ha tenido el sistema de formación inicial desde el cierre del modelo normalista, no es algo que se haya planteado hasta esta administración.

De hecho, ha sido un reclamo permanente del magisterio y de diferentes sectores. Yo creo que el INFOD se ha pensado de muchas formas en diferentes coyunturas. Ahora la historia de este INFOD tiene que ver con el planteamiento del ministro (Carlos) Canjura respecto de la creación de un sistema nacional de profesionalización docente que lo concibe con tres patas, ¿no? Tres columnas fundamentales. Una, la formación en servicios. Eso se hizo a través del Plan Nacional de Formación Docente. En segundo lugar, la dignificación de la carrera docente, las medidas de dignificación, de mejora y finalmente, un tercer momento que es la dinamización de la formación inicial docente. Esta dinamización la planteábamos nosotros inicialmente con la creación de un instituto nacional que más que formar docentes dinamizara el sistema con medidas de políticas más bien asociadas a la creación del conocimiento, a la formación de formadores y al establecimiento de una nueva serie de criterios que garantizaran una mejor oferta de mayor calidad. Ese es el INFOD que 
el 22 de junio de 2017 anunció el presidente Salvador Sánchez Cerén. Pero entre el 22 de junio de ese año y el 20 de febrero, de 2018, pasaron muchas cosas. La fracción legislativa del FMLN representada a la Comisión de Educación y Cultura de la Asamblea Legislativa impulsó también una propuesta que estaba más, digámoslo así, focalizada en la formación inicial docente. En brindar, en ofertar formación inicial docente. Y ellos desde el principio plantearon el INFOD como una nueva institución de educación superior. Finalmente, después de las consultas que hicieron a diferentes sectores, al magisterio, al Ministerio de Educación, se aprobó la ley de creación del INFOD que claramente es un híbrido de ambos esfuerzos. Pero este híbrido tiene limitaciones que están planteadas por la definición misma que tiene la ley dentro del INFOD que lo define como institución de educación superior. $\mathrm{Y}$ si nos atenemos a lo que establece la Ley de Educación Superior, dentro de las formas que puede adoptar una institución de educación superior, el INFOD no es una universidad, sino que es un instituto especializado. Un instituto especializado para la formación de docentes en todas las modalidades en servicio, en formación inicial docente, y también en los procesos de especialización y de formación continua del magisterio. Eso está acompañado con tareas relacionadas con la investigación educativa, con tareas de apoyo a la certificación y acreditación del resto de instituciones. No somos la institución acreditadora ni certificadora. No podemos serlo. Sigue siendo el MINED. Tampoco somos la instancia evaluadora del resto, sino que somos una instancia de apoyo. Digamos que la ley de creación del INFOD viene y le dice al Ministerio de Educación: «¿Usted quiere desarrollar procesos de formación y evaluación?
Apóyese técnicamente en el INFOD». Pero el INFOD tanto en institución formadora, institución de educación superior, también debe someterse a esos procesos.

\section{E1 INFOD está formando docentes, pero cuál es la diferencia de que un docente se forme con ellos o en una universidad.}

Yo creo que el plus del INFOD es que es esa instancia inmediatamente articulada con el Ministerio de Educación. Como el instituto se sostiene con fondos públicos puede fácilmente atender aquellas otras áreas, por ejemplo, formar a profesores de matemáticas, de educación artística y de todas aquellas áreas que el resto de instituciones formadoras dicen: «no tenemos demandas para poder atenderla». Entonces el INFOD sería ciertamente una medida del Estado para garantizar que en estas especialidades, a través de una acción afirmativa, se generan los profesores y las condiciones para que en estas áreas podamos contar con recurso humano.

\section{Carlos Rodríguez habla de la oferta $y$ demanda de las carreras pedagógicas en las universidades. Cabe preguntarnos entonces, ¿quién quiere ser maestro?}

Lamentablemente, desde hace mucho tiempo, la profesión docente ha pasado a ser una opción de segunda o de tercera categoría y esto lo digo sin menospreciar al grupo de personas que todavía quieren ser docentes por vocación porque hay un buen grupo de personas en El Salvador, un grupo de salvadoreños y salvadoreñas que sí quieren ser docentes por vocación. Pero lamentablemente es el grupo más reducido. $\mathrm{Y}$ en este sentido, la mayoría de los que quieren ser docentes en El Salvador no tienen, tal vez, otra alternativa de formación profesional rápida, asumen en 
su autodiagnóstico que otras áreas científicas, técnicas o de las humanidades les representan una mayor dificultad y lamentablemente terminan optando por estudiar una carrera de pedagogía o entrar al magisterio. Esto tiene muchas explicaciones a la base, muchas causas, muchas razones. Entre otras, el desentendimiento del Estado respecto de la formación inicial docente. Es decir, haberla dejado en buena medida a la suerte de las dinámicas generadas por 18 instituciones, 17 privadas, solo la UES (Universidad de El Salvador) es pública, en buena medida eso ha representado una caída considerable de la calidad de los procesos formativos, una ausencia también del Estado de políticas que incentiven, que atraigan a los docentes, a futuros docentes. En buena medida eso tiene que ver con su desprestigio pero también el debilitamiento de la profesión docente y de la carrera docente en términos de valoración social también tiene que ver también con aspectos económicos. Tiene que ver también con la misma práctica docente en que se ha convertido hoy. Obviamente la sociedad de finales del XIX y la primera parte del siglo XX, los primeros 50 años del siglo $\mathrm{XX}$, el docente era un referente ético, político, cultural y científico. Hoy el docente se ha transformado en algo más que eso. Y cuando digo algo más no necesariamente es algo coherente con la función que debería de tener asignada. Tenemos un docente agobiado por el docentismo, hemos convertido al docente en alguien que solo da clases, la dinámica social, la fragmentación y la gran cantidad de conflictividad social acumulada también lo ha puesto en dificultades para ser un gestionador de esa conflictividad y eso también se ha reflejado, digamos, en una cierta desvalorización social de lo que representó en siglos y décadas anteriores y desde luego a la misma condición económica salarial del docente que es terrible. Ahora, ¿quién quiere ser docente en un país donde retirarse es poner en riesgo su situación de vida digna? ¿Quién quiere ser docente en un país así? Pues tal vez solo los que no están informados de que al retirarse van a tener una pensión de 240 dólares.

\section{Las precarias condiciones de retiro y la desvalorización de la profesión son cosas que el Estado debería cambiar o debió cambiar. ¿Por qué no lo han hecho en 10 años?}

Bueno yo creo que aunque seás Gobierno no tenés que perder la perspectiva crítica de lo que hacés como Gobierno. Finalmente es la misma situación, creo que es más penoso negar una situación que es real.

Yo creo que esta situación del magisterio, situación salarial, hay que verla históricamente, también. Y con esto no estoy planteando un desentendimiento del Gobierno actual, porque es oportuno recordar que desde el año 96 tenemos una Ley de Carrera Docente y desde ese momento venimos construyendo esta profesión docente que tenemos hoy.

La situación de la carrera docentees algo que nos ha afectado y nos sigue afectando y que hay que reconocer que hemos sido incapaces de cambiarlo a nivel legal, que es una de las principales dificultades que tenemos. Pero también hay que decirlo que la ausencia de recursos es en definitiva un factor clave y muy probablemente además de lo que no hizo el Gobierno hay que agregar que la sociedad en su conjunto y los diferentes referentes dela sociedad, no solo el Gobierno, pues, realmente hacemos muy poco para cambiar la situación de los docentes. Te lo pongo en perspectiva, cuando 
pensamos en el docente pensamos en contratar a alguien para dar clases y nos preocupa que no dé clases y nos preocupa cuántas horas clase nos hace falta cubrir. Ese es el sentido que tenemos de la profesión docente. Por supuesto que es importante garantizar que haya alguien que esté dando clases en las horas que tenemos pactadas como sociedad. Pero el docente no puede ser aquella persona en la que confiamos solo para dar clases. Buena parte de lo que el país tiene que hacer para cambiar la situación generalizada de la profesión docente y la situación crítica en la que se encuentra en términos salariales, en términos de la valoración social, en términos de las condiciones para el ejercicio de su carrera docente, en parte tiene que ver con cambiar el sentido que tenemos todos del profesor y de la profesora.

\section{Esta es una pregunta que le hice al ministro} Carlos Canjura y creo que es válida por el escenario que tanto Canjura como vos pintan: ¿Hay que seguir capacitando docente o es mejor darle un F5, un refresh y empezar de nuevo?

Nada en la sociedad es posible borrarlo y empezar de nuevo. Siempre está la carga de la tradición, la carga de lo que has hecho. Todos tenemos que cargar con eso, como sociedad como Gobierno. Esa es una condición sin la cual no podés construir nuevos proyectos. Yo pienso que el país tuvo la oportunidad de tener un gran acuerdo que en cierta forma de eso quedó el plan El Salvador Educado. En el Consejo Nacional de Educación estaban: El Gobierno, estaban organizaciones internacionales, universidades, empresa privada y también estaban la sociedad civil en general. Yo creo que ese espacio era el espacio para garantizar un acuerdo que permitiera compromisos fiscales $\mathrm{y}$ en los compromisos fiscales no solo va el compromiso del Gobierno para crear mejores políticas fiscales sino el compromiso de nosotros como contribuyentes. Porque buena parte de lo que hay que hacer, en efecto, es administrar mejor los recursos del Estado, distribuirlos mejor, pero también tenemos que recaudar más impuestos y los salvadoreños finalmente tenemos que comprometernos, sobre todo los que tenemos más recursos, con garantizar que el Estado pueda tener recursos para que tratemos mejor a los docentes. Es decir, con esto lo que quiero plantear es no una ausencia de reconocimiento de lo que no hicimos, siempre se puede hacer más, yo solo trato de poner en perspectiva algo que es fundamental. Sin acuerdo nacional y sin acciones de todos los agentes de la sociedad no vamos a poder mejorar la condición de los docentes.

¿Entonces cómo seguimos capacitando docentes y cómo los evaluamos a ellos y evaluamos el método que utilizamos para seguir capacitando?

Eso creo yo que es muy importante. Todo el sistema de evaluación que construimos en el sistema de educación de los aprendizajes. ¿Y al centro quién está? ¿Quién está siendo interpelado por los instrumentos de evaluación que tenemos? Y eso es así desde el principio de la reforma educativa la que está todavía vigente; o sea, los pilares de la reforma educativa en marcha, en cierta forma están vigentes. O sea, los pilares de la reforma educativa en marcha en cierta forma están vigentes. Transformar el sistema educativo más que demandar una nueva reforma, lo que demanda es una contrarreforma. Hay que desmontar los pilares de la reforma educativa que vio el proceso de evaluación como el que solo se interpela al estudiante, a través de la prueba estandarizada nacional que es la PAES. No es cierto que nos dé información 
clara la PAES sobre cómo están los docentes. Solo nos dice, nosotros inferimos que si el estudiante sale mal en sociales omatemáticas, tenemos malos profesores de matemáticas. $Y$ si sale mal, como ocurrió hoy, el departamento que tiene las menores calificaciones es Usulután, podemos inferir que en Usulután están los profesores que tienen mayores deficiencias, pero es una mera inferencia que no se sostiene a la hora de reclamar más detalles de lo que es esa condición. Nosotros hemos carecido históricamente de un proceso de evaluación de la formación docente y de un proceso de evaluación de los docentes. Y me cuido de no señalar evaluación del desempeño docente, porque la evaluación docente es algo mucho más amplio que medir específicamente el desempeño de ellos. La evaluación docente debería involucrar también aspectos de su formación, de sus condiciones de trabajo, de los recursos con los que cuentan, de cómo usan los recursos, entre otros aspectos. Entonces, hace falta también un sistema que evalúe las diferentes esferas del sistema educativo. No es correcto que las cosas vayan mal solo si los docentes están mal. Tenemos una gran deuda, por ejemplo, en términos de gestión directiva. El director también tiene un papel clave de lo que ocurre en la escuela. La comunidad también tiene un papel clave. Hay escuelas que tienen mucho éxito en buena medida por el compromiso de los padres de familia con los procesos que se están dando en la escuela. En este quinquenio se planteó la necesidad de construir un sistema nacional de evaluación que integrara todos estos elementos. Yo creo que ese sistema ha tenido diferentes dificultades, entre ellos la inercia misma del sistema a ser evaluado.
Parece que le tenemos miedo a evaluar a los docentes. ¿Por qué nos cuesta tanto?

Yo creo que los ejercicios que se hicieron en el pasado,losintentos de iniciar proceso de evaluación dejaron una carga que nos sigue en cierta forma haciendo una mala jugada. En América Latina, sobre todo te lo dicen en la experiencia chilena, «tengan cuidado con relacionar evaluación con bonificaciones».Distingámoslas. La evaluación como sistema educativo en primer lugar debe hacerse como un proceso en el que el sistema quiere mejorar porque quiere ser mejor, porque tiende a ser mejor. Hagamos otro tipo de procesos para identificar a quiénes vamos a reconocerles un aporte especial. Entonces el ejercicio que se hizo aquí de evaluación inicial asociado a bonos a las escuelas creo yo que nos dejó un antecedente negativo. Aquí es sentarnos todos y cuando digo sentarnos me refiero a funcionarios, empresa privada, incluso estudiantes, padres y madres de familia y magisterio a resignificar lo que es evaluarnos como educadores. Porque desde mi perspectiva el docente es un educador. También el funcionario, el técnico del MINED debe asumirse como educador, pero no en ejercicio de la docencia, pero sí aportando al proceso educativo. $\mathrm{Y}$ en ese sentido también tienen que evaluarlos.

Hablás de un grupo de maestros graduados con vocación. ¿Cómo logramos que este grupo no pasé 10 o 15 años esperando turno para entrar en el sistema educativo?

Lo primero es reformar la forma en que hacemos los procesos de selección. La Ley de la Carrera Docente en ese sentido ha tenido una enorme deficiencia que ha privilegiado los años de espera.Ha dado lugar a algunas prácticas que definitivamente no benefician al sistema educativo para la mejora continua pero hay ejercicios interesantes. 
Creo yo que este decreto 753 de reciente aprobación en la Asamblea Legislativa que plantea una reforma transitoria a dos aspectos importantes: Uno, que las contrataciones que se hagan en 2018 primero se hagan de docentes que nunca han tenido una plaza. Eso te permite darle ingreso a los que calculamos son 40 mil que nunca han ejercido la docencia.

Y luego, el decreto plantea otro punto que es interesante, que estas plazas se asignen por necesidad en algunas especialidades. Ha sido el primer ejercicio. Nosotros cada año estamos contratando 971 docentes. Este año son 971. El año pasado anduvo por la misma cantidad. Esto te genera un problema bien interesante, el ministerio hizo un programa todavía muy modesto pero que lanza cosas interesantes de acompañamiento a docentes nóveles. A propósito de esta reforma transitoria a la Ley de la Carrera Docente.

En América Latina es una verdad aceptada que vos podés garantizar que los docentes se queden en el sistema y tengan un mejor ejercicio profesional si los acompañás en los primeros años. El país nunca ha tenido procesos de acompañamiento de docentes nóveles hasta hoy con este ejercicio muy modesto. $\mathrm{Y}$ te voy a dar algunos datos interesantes. Primero, de los 971 que llegaron, todos andan [risas] entre 10 y 20 años de haberse graduado sin haber ejercido la docencia.

Yo conversaba con la persona responsable y le decía: «Por favor, deme toda la información que tenga al respecto, si hicieron entrevistas». Porque nunca habíamos tenido una fuente directa de la situación en la que están los famosos 40 mil.
Ahí tenemos personas que están en una condición paupérrima, increíble, y ganaron una plaza. Tenemos personas que se graduaron hace 10 o 20 años, como te decía, y tienen 15 años de no haber dado clases. Esa es una realidad a la que no podemos darle la espalda a la hora de pensar en dinamizar la planta docente actual. Ahora, este proceso acompañado de algunas medidas, creo yo, importantes pero todavía modestas los acompañó, les dio talleres para recordar cómo se planifica, una revisión curricular de sus áreas, pero efectivamente no podemos garantizar que con eso este grupo de nuevos docentes van a tener el desempeño que esperamos.

Entonces la fórmula sencilla que se plantea a veces de «mire, eche mano de los 40 mil que tiene graduados para poder dinamizar el sistema» representa grandes retos que tiene que ver con recursos y formación a este grupo. Ahora, ¿qué hacemos nosotros con las 971 plazas que se liberan? Nada. $\mathrm{O}$ casi nada. Haciendo números así rápidos yo te podría decir que en cada especialidad para atender a los estudiantes que tenemos en tercer ciclo y media, necesitamos por cada especialidad entre 8 mil y 10 mil docentes. Entonces hagamos cuentas de cuántos tenemos en algunas especialidades. El tema que está de moda: inglés, 2 mil 900 profesores de inglés. Profesores y profesoras.

Necesito 5 mil o 6 mil docentes más, solo esas 971 son nada para poder cubrir esa demanda. Educación artística, el último observatorio dice que ya tenemos 800 . Eso seguramente tiene que ver por los que se están formando que ahora se autodefinen como profesores de educación artística, porque hace dos años solo reportaban 600, 614 más o menos. Vaya esos son profesores 
de educación artística para educación básica. Vaya, ahí necesito 4 mil, me hacen falta 3 mil 200. Y vamos por otras áreas, vamos por matemáticas, que ya creció el número de profesores de matemáticas en este quinquenio. Al principio, como por el 2014 teníamos 2 mil 900; ahorita ya se reportan cerca de 4 mil profesores de matemáticas. Ese es el proceso de especialización en el que hemos estado, los nuevos que han entrado.

Pero necesito entre 8 mil y 10 mil. Creo que el ICEFI es el que hizo un cálculo de que se necesitaban 35 mil docentes. Pero creo que todavía es un cálculo modesto, si pensamos en cobertura total en alguna áreas, como educación inicial o primera infancia, por ejemplo. Es decir, para mí la inversión del Estado tiene que ir en generar programas de atención a los docentes nóveles, que ya tienen un buen rato de estar fuera, en generar programas de acompañamiento a la práctica pedagógica de los que se van graduando.

Porque ocurre también el prejuicio, bueno, que no es tanto un prejuicio, sino que hay razón de decir: «¿Cuántos años de experiencia tiene usted para valorar si lo puedo contratar para algo o no?». No es algo tan descabellado, todos queremos personas que estén preparadas, en este sentido, mejorar la forma en que las universidades se conectan con el sistema educativo para tener unas mejores prácticas pedagógicas en el proceso formativo es central para identificar futuros formadores de calidad. Luego, si no hay nuevas plazas no vamos a poder atender la demanda. Y, de nuevo, si no reconfiguramos la planta docente nacional especializando y poniendo a cada quien a hacer lo que le corresponde en la medida de su formación y su especialidad, no vamos a poder ordenar toda la cancha.
A este Gobierno le queda poco menos de seis meses. ¿Cómo logramos que el orden como mantienen la cancha, como tu decís, se mantenga más allá del 30 de mayo?.

Ahí es donde, lamentablemente, el debilitamiento delCONED no nos ayuda definitivamente. O sea, el CONED como referente de la sociedad para filtrar las políticas educativas y además incidir en la toma de decisiones es importantísimo. Un CONED fuerte. Un CONED que haga contrapeso, a esa redefinición, reacomodo, de cada quinquenio. Debimos haber posicionado mejor el Plan El Salvador Educado. Eso sin duda era una necesidad como acuerdo nacional. Ahí hay que trabajar mucho todavía. Todavía hay tiempo para en estos seis meses reposicionar el CONED, no solo con los candidatos, sino con el futuro Gobierno este tema. Ahí tenemos nosotros una propuesta de transformación de la educación para 10 años, a la que perfectamente podrían atenerse los diferentes candidatos, tenerlo como referente, pero ahí necesitamos más gestión política de los concejales, no solo del ministro, del Gobierno central también. Más gestión política al respecto. Pero hay una cosa que creo yo hace falta también y que puede ayudar mucho, nosotros en estos seis meses estamos trabajando en eso. Nosotros vamos a entregar un documento al futuro presidente. «Presidente, esto se avanzó y esto hace falta en política de formación docente». Creo que los últimos dos quinquenios, bien o mal, han puesto al centro la formación docente, sin duda. Y han puesto al centro una necesidad también, de generar política quinquenal de formación docente. El INFOD creo yo que tiene que aportar con un claro posicionamiento respecto de los avances y un posicionamiento crítico respecto de lo 
que hace falta, respecto de las necesidades de formación para el nuevo quinquenio. En la ley de formación del INFOD se establece algo que no es del todo claro. Tal vez pudo haberse redactado mejor, pero nos da un marco de acción importante. La ley dice que nosotros tenemos que definir una política nacional de formación docente. Esta no es una normativa, ahí es donde la gestión política es importante, ahí es donde la elaboración y el aparato crítico de donde se levanta una política quinquenal en tanto que se construya sobre la base de evidencias.

En tanto que también la construyamos con el resto de instituciones formadoras. En tanto que también metamos en esto a FUSADES, en tanto que metamos a las diferentes instancias que pueden posicionar una política o la necesidad de una política en los siguientes cinco años. Ahora, no todo es formación docente, hay temas que también se quedaron pendientes y que también hay que posicionarlos. El tema de evaluación es un asunto clave. La misma estructura del Ministerio de Educación es un asunto clave. El tema de ciencia y tecnología.

Pasamos a la pregunta de rigor. ¿¿Después de 10 años no habría que hacer una actualización de los programas de estudio?

Bueno, hay unos programas que tienen más de 10 años. Porque si tomás en consideración que algunos ya estaban listos en el 2006, o sea, ya tenemos 12 años de algunos programas.

La norma es cambiarlos cada 10 años en el país. O sea, si hacés memoria entre el año 94 y 96 se generaron los anteriores a los que tenemos todavía vigentes.
Yo creo que el problema del cambio curricular, de la dinamización,cambio, actualización, hay muchas formas de decirlo.

El problema que tenemos, entre otros, es de capacidades instaladas. Vos vas al Ministerio de Educación y pásate por todas las direcciones de nivel y te diría yo: «Indentificá las unidades de desarrollo curricular. Identifícalas y mirá si hay gente de todas las áreas, de todas las especialidades y te vas a dar cuenta que tenemos una gran dificultad de capacidades instaladas.

O sea, yo te puedo decir, por ejemplo, que hay niveles en los que no hay especialistas de Estudios Sociales, que te puedan también dar seguimiento.

Porque el asunto es también que el tema con el currículo, es que vos necesitás un área en el Ministerio de Educación que esté permanentemente haciendo evaluación curricular y que en el momento que se tome la decisión política, de cambiar el currículo vos tengás unos insumos. Pero yo, por ejemplo, que he estado insistiendo en la dinamización de la evaluación curricular de Estudios Sociales, y que la estamos haciendo, yo no te podría decir que tengo un referente al cual decirle: "Mire, ¿qué tienen ustedes como insumo en estos 12 años?». Hay un problema estructural de capacidad instalada. No tenemos unidades de curriculares a la altura de lo que significa hacer transformaciones del currículo, evaluaciones o revisiones permanentes. Ese es un problema. Ahora, yo creo que la estrategia del ministro es acertada.

$\mathrm{El}$ problema es que requiere más tiempo, como bien lo ha señalado. Él parte de una premisa: 
¿Qué sentido tiene un cambio curricular en el que los docentes no hayan estado involucrados? Entonces, ¿Qué pasa si no nos involucramos? El proceso de recepción y de asimilación de ese currículo también va a llevar un tiempo.

Un tiempo mayor que sí hemos involucrado desde el principio a la planta docente. Entonces la estrategia nuestra fue: «Bien, parte del proceso de revisión curricular es la formación en servicio». La formación en servicio debe diseñarse de tal manera que genere un espacio para intercambiar sobre lo que hay que cambiar en el currículo.

Yo coordiné la formación en Ciencias Sociales. De hecho, de entrada no le llamamos especialización ni Estudios Sociales, porque ellos tienen un título para ser profesores de Estudios Sociales. Nosotros les llamamos Especialización en Ciencias Sociales, porque nuestra intención desde el principio era darle un carácter científico a la formación de ellos. Ya eso es, en buena medida, un cambio curricular que no está expresado todavía en los programas porque también el currículo hay que entenderlo como algo más amplio que los programas. Ahora, si no cambiamos los programas también no estamos en nada.

Entonces nosotros en el caso de Estudios Sociales hicimos ese diálogo con los docentes, con los 300 especialistas y también con los docentes que formamos en especialización que son alrededor de 2 mil 350; es decir, estamos hablando de un grupo de consulta y de discusión permanente sobre los programas de Estudios Sociales que anda entre los 2 mil 700 docentes, una buena muestra porque es una muestra nacional. Son 8 mil docentes de Sociales los que tenemos. Y bueno ahí encontramos motivos, construimos una planta de especialistas, construimos también una planta de expertos, los que nosotros llamamos expertos son: docentes universitarios que tienen una trayectoria importante en una especialidad y trabajaron dos años y medio con los docentes. ¿Hoy cómo hemos articulado el proceso de revisión curricular? Primero, los especialistas son los que están en el diseño, los coordinadores son los expertos.

$\mathrm{Y}$ así es como se parte de una claridad, una claridad que tiene que estar constantemente retroalimentándose porque estamos ya diseñando toda la consulta para el próximo año, pero además hay procesos que alimentaron esto. Por ejemplo, todos los especialistas acreditados del país, que son como 930, entraron en un proceso de propuestas técnicas y uno de los temas era la revisión curricular y una de las áreas es Sociales. Ellos nos han entregado un cúmulo de propuestas para eso que ha sido integrado en la revisión curricular que estamos haciendo.

El currículo, lamentablemente en su totalidad no ha sido cambiado integralmente sino que hemos ido por partes. Matemáticas completó su ciclo prácticamente. Apenas va iniciando Lenguaje. Sociales este año. Tenemos nuevos programas de educación artística, eso sí. Pero sí hay que ser autocríticos y aceptar que no pudimos construir unidad curricular.

Hay algunos motivos que articulan todos los procesos, pero si vos me preguntaras: «Bueno, ¿y cuál es el enfoque curricular del Ministerio de Educación hoy?» Nosotros, por ejemplo, estábamos trabajando con el enfoque socioformativo y yo estoy casi seguro que hay 
otras áreas que están trabajando en otro enfoque. Ahí tenemos una tarea importante para el siguiente Gobierno. Es decir, lograr una unidad curricular, una articulación del currículo nacional pero que también los cambios curriculares por área completen su ciclo y eso sí lo estamos ensayando nosotros como Sociales.

Vamos a cambiar los programas de los primeros niveles pero también vamos a cambiar el de la formación de educadores para esa especialidad. Tenemos el problema que cambiás el programa de Estudios Sociales para los niños y los jóvenes pero dejás igual el profesorado y la licenciatura. Entonces sí es algo que nosotros lo estamos ensayando.

\section{Hay un loop entre la actualización de currículo} y la actualización de docente. ¿Quién debería formar a los formadores? ¿Cuál es ese perfil? Esa es una discusión que está al centro del enfoque, porque la tarea que nos dio el ministro Canjura es concentrarnos en esta, primera fase, en fortalecer las competencias de quienes forman a los futuros docentes, es decir, no nos referimos a los especialistas en formación docente, que son formadores de docentes.

Pero son formadores en servicio. Nosotros nos referimos a los formadores de las instituciones de educación superior que tienen programas de formación inicial, es decir, docentes universitarios. Nosotros hemos realizado un diagnóstico del perfil de estos formadores de docentes. $\mathrm{Y}$ ciertamente es muy coherente con la situación general que tenemos en la educación superior. Muy pocos tienen formación doctoral, hay muchos que tienen maestría. Lamentablemente algunos de estos programas son muy genéricos. Muy en el sentido de la tradición de las ciencias de la educación en E1 Salvador, que es una formación muy general. Pero tenemos pocos con doctorados. Como tenemos pocos con doctorados, es claro que hay muy pocas publicaciones y por lo tanto, hay muy poca investigación. Es una planta muy joven, que anda entres los 25 y los 29 años. Eso es muy positivo para nosotros. Es decir, tienen todo el tiempo para seguirse formando, hay que ponerles condiciones para formarse.

Pero a la base hay un problema, cuando vos vas a las planta de profesores en muchas instituciones la proporción hora clase/docente de planta es seis a uno. Seis horas clase por cada docente de planta. El "hora clase" es aquel profesor que tiene las condiciones más adversas para poder desempeñarse profesionalmente. Trabaja en tres o cuatro universidades.

Da cinco o seis materias para hacerse un salario. ¿En qué momento va a investigar? ¿Cuáles son sus estímulos? Es decir, nosotros tenemos que pensar no solo en el docente que queremos, en el formador de docente que queremos en términos de competencia y sus condiciones.

Porque si no tenemos unas condiciones adecuadas no podemos estarle exigiendo doctorado a estas personas. No podemos estarle exigiendo que publique tres artículos al año. No podemos pedirles que hagan investigación educativa. ¿Cómo van a acompañar la práctica pedagógica de los estudiantes? Por ejemplo, en la Universidad de El Salvador, no es un dato tan preciso pero basta ir a boca de urna y revisar las asesorías de tesis. $\mathrm{Y}$ vos la mayoría de tesis tenés un asesor por cada 10 estudiantes. No que esté revisando 10 tesis, está revisando tesis que 
cada tesis está hecha por 10 estudiantes. Porque claro, la masa de estudiantes es tan grande que los obliga a eso, ¿no? Entonces nosotros estamos pensando que es necesario poner esto en la discusión pública.

El INFOD no puede obligar a ninguna institución a que mejore las condiciones de los docentes. El Ministerio de Educación no lo ha podido hacer en años. $\mathrm{Y}$ es que no se trata de obligar, se trata de llegar a un acuerdo nacional de redefinir prioridades. $Y$ si es necesario tener mejores docentes, entonces tenemos que tener mejores formadores de docentes, mejor preparados, pero también con mejores condiciones para el ejercicio profesional.

\section{¿Qué países tiene como modelos El Salvador para la formación de sus docentes?}

Nosotros tenemos que abrirnos a las experiencias de América Latina y el mundo en ciertas áreas, ciertos temas porque es un cliché decir que nuestro modelo debería ser el modelo nórdico, europeo. Pues sí, todos quieren ser como Dinamarca, Noruega y Finlandia. Claro, en buena medida hay que tener docentes sometidos a esos niveles de exigencia de calidad, a esos niveles de formación y a esos niveles de reconocimiento salarial y social. Por supuesto, eso es indiscutible. Ahora, es importante también que nos abramos a experiencias que están más en Latinoamérica también.

Nosotros, por ejemplo, tenemos que abrirnos a la formación de docentes con perspectiva intercultural. Guatemala ha avanzado en eso más que nosotros por obvias razones, pero eso no significa que nosotros no tengamos una tarea pendiente en ese sentido. Nuestra sociedad no es homogénea, ninguna sociedad es homogénea.
Yo creo que hay experiencias interesantes de formación ciudadana, de fortalecimiento de capacidades docentes para la formación de ciudadanía en Colombia. Tenemos que abrirnos, por ejemplo, al tema de la formación de docentes para la ruralidad. Algo para lo que nos hemos cerrado por años en el país y tenemos casi la mitad de escuelas multigrado en el mundo rural.

Creo que es importante abrirse a experiencias de centros de investigación como las que están ocurriendo en Chile. Como en la Universidad de Chile con este centro que denominaron "Saberes Docentes", eso es muy importante. Creo yo que es importante abrirse a experiencias de mejoras continúa de la profesión docente de evaluación como la que está teniendo el mismo Chile o Ecuador. Tenemos que aprender también de las malas experiencias.

Ahorita en México, López Obrador detuvo la reforma educativa, dijo: «No más». Y el Instituto de Evaluación Educativa de México está en una situación de redefinición.

Y por qué, porque la sociedad percibió que su labor era una labor asociada a aspectos punitivos, más que a promoción de la mejora continua de la calidad educativa. Entonces el instituto está en una encrucijada. Nosotros tenemos una deuda pendiente en evaluación docente, pues tenemos que aprender mucho de esas experiencias.

\section{Rosario Melgar de Varela y Consuelo Cabezas de Linqui}

El exministro Carlos Canjura enumeró, en su entrevista, una serie de hechos en los años 70 y 80 que perjudicaron la educación del país y 
termina: "Todo esto se corona con el cierre de la Escuela Normal para entregárselo a un batallón. Esa es otra grosería que refleja el poco peso que le concedíamos a la educación".

Las escuelas normales siempre han sido un mito en cuanto a la discusión de educación en El Salvador, por eso entrevistamos a dos normalistas. Para saber y entender qué eran, qué enseñaban y cómo enseñaban, entrevistamos a Rosario Melgar de Varela y Consuelo Cabezas de Linqui, ambas trabajan en el departamento de Planificación Educativa de la Universidad Francisco Gavidia. Rosario es la directora y Consuelo es la asistente del departamento. Ellas han trabajado juntas en educación por más de 60 años.

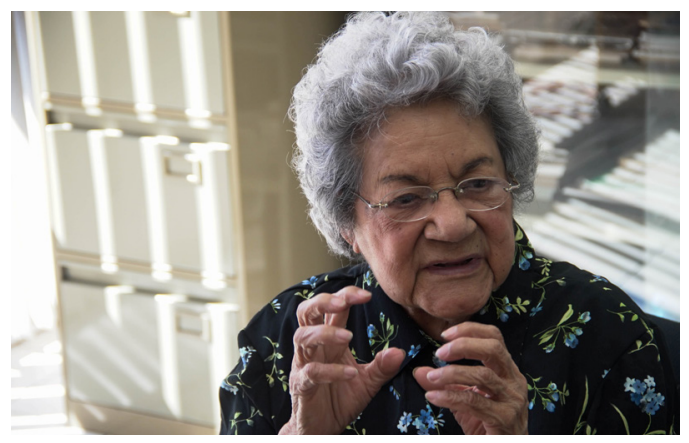

y que van a ayudar a la sociedad porque es la educación la que tiene la voz de por medio. Cosa que se ha perdido mucho esa mística, porque en ese tiempo que estaba estudiando para normalista a tiempo completo y no había alternativa más que esa. En ese tiempo que fue una época que pues... fue una época que yo la considero muy buena, porque fue de formación para nosotros que nos graduamos y tuvimos unos docentes reconocidos. Bueno, la señora Melida Anaya Montes era la subdirectora, recia, pero muy buena gente. Pero sí le digo había un compromiso de la institución con la formación de todas las que estudiamos ahí.

Era muy estricto, porque ahí desde el uniforme todo mundo tenía que ir como se ordenaba

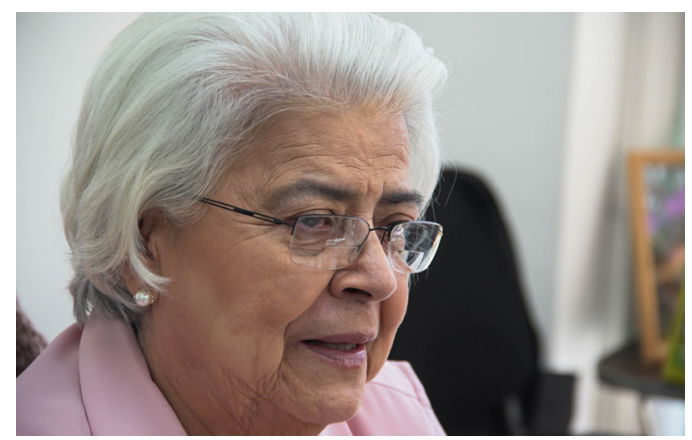

Imágenes 3 y 4. Maestras normalistas Consuelo Cabezas de Linqui (izquerda) y Rosario Melgar de Varela (derecha). Fotos: Raúl E. Benítez, periodista multimedia.

\section{Rosario nos cuenta qué tenían de especial las Escuelas Normales}

Rosario Melgar de Varela:La mística.Yo me gradué de la Normal de Maestros España, la Escuela Normal España como cualquier institución educativa tiene sus normas, sus principios y tiene su obligación para con los estudiantes de formarlos, de protegerlos y de inculcar en ellos aquellos principios que van a favorecerlos a ellos porque de lo contrario lo castigaban y las internas no salían, y las externas teníamos que llegar el día sábado y domingo a estudiar a la Normal por andar las medias debajo de las rodillas o por haber cometido algún error.

Un día normal empezábamos con Idioma Nacional. Pero el currículo que tenía la Normal era un currículo específico, primero generalizaba y después ya íbamos al área especializada, al área 
académica ya de la carrera. Ahí nos dieron todas las bases pedagógicas para poder ejercer la labor docente. Y le digo, estudiábamos todos los días y teníamos un pool de docentes excelentes, gente calificada, gente muy buena. Los valores que usted debe llevar siempre, los que ha adquirido en su casa, en las instituciones donde se forma y lo que va a ir a inculcar cómo va a tratar a los estudiantes porque son seres humanos, y tienen diferentes edades y cada edad de su vida tiene un componente especial. Cómo tratar a los infantiles, cómo tratar a los jóvenes y luego a los adultos. Hay una pedagogía para cada uno de ellos.

\section{Rosario cree que aparte de estudiar en la Escuela Normal España hubo otra cosa que determinó su carrera como docente.}

Rosario Melgar de Varela: $Y$ esto que tuvimos una suerte de que nos nombraran en una escuela experimental aquí en San Salvador, que era un modelo de escuela.

Consuelo se une a la conversación y juntas nos cuentan qué era una escuela experimental, cuál era la diferencia.

\section{Rosario Melgar de Varela: Nosotros} trabajábamos con unidades de trabajo y para los niños con los centros de interés. Esas unidades de trabajo eran, por ejemplo, protejamos nuestra salud». Ahí va todo lo relacionado con la salud, con lo que es el cuerpo humano, era una... No es que nosotras como mayores estemos jay! lamentándonos. No, es la realidad. Había orden, había disciplina, se veía que la enseñanza pegaba.

Consuelo Cabezas de Linqui: En las unidades de trabajo y en los centros de interés el aprendizaje tenía un enfoque metodológico integral, como mencionó ella. La salud, pero de la salud venían a salir ya las materias. Por ejemplo, qué alimentos. Y de ahí es ir dándole la orientación a la alimentación. ¿Qué costos tienen estos? Las matemáticas, ¿̇con qué otro nombre se conocen los alimentos? Iba el lenguaje. Eso era el enfoque principal que tenían estas escuelas.

El aprendizaje era integrado. No se ve que el Idioma Nacional tiene que ver con una cosa y que Sociales tiene que ver con otra; sino que ahí se amarraba todo. En matemáticas, qué precios tienen los alimentos y cómo podían ellos hacer presupuestos y cómo podían hacer su guía para una buena alimentación. Y todo esto iba, pero sobre todo trabajamos en el triángulo que siempre ha existido: estudiante, maestro, padres de familia.

Los padres de familia estaban interesados en conocer qué iban a aprender sus hijos y cómo debían aprenderlo y qué integración debían de tener ellos con sus hijos y con nosotros, los maestros. Hoy, ¿Qué le dicen actualmente (al alumno)? investigue y solo le dan el título y el internet. Pero ahí copiar lo que está en el internet.

Pero cuál es la idea central de ese tema, no lo dicen, y muchos menos utilizarán guía para que ellos investiguen. El profesor sabe de un tema pues puede ser el principal, pero el alumno no.

Así es desde el principio o lo que a él le gustaría copiar.

Pero el enfoque este de la escuela experimental era que había esa integración y el Gobierno estudiantil apegado, integrado con la metodología 
de aprendizaje era el que les desarrollaba la personalidad a los estudiantes. Mire, una cosa bien clara, qué en educación se tiene que ver lo qué es educación y lo qué es instrucción. En la instrucción usted le da los temas teóricos, pero en la educación ahí sí se ve la formación de actitudes, desarrollo de conductas, la misma metodología, eso es lo que ayuda a que un ser humano se eduque y no solamente se instruya.

Para instruirse están los libros y lo que ahorita está en boga. Si nosotros hicimos una investigación también con el doctor Óscar (Picardo) en las escuelas y fuimos a ver a los alumnos... La maestra sentada ahí, solo viendo a los alumnos haciendo desorden, que no había disciplina. Y les decían: "Bueno, van a copiar, de aquí hasta aquî". Copiar y ya, esa era toda la clase.

No había esa integración de ellos de decirle: "guarde todo ese documento", documentar cuál es lo principal y qué le hicieron sentir.

Hay muchas escuelas que todavía están trabajando con algunas metodologías, por ejemplo le puedo mencionar a la escuela España, a la Escuela Concha Viuda de Escalón, a la escuela Jorge Lardé, que todavía siguen algunas metodologías porque fueron maestros que se formaron y no han olvidado esa mística de trabajo. Nos doblaron y ese fue el fracaso de las escuelas experimentales, que doblaron la escuela. Estoy hablando del 65, que fue aquel gran terremoto y que muchas escuelas se cayeron. Entonces las escuelas que doblaron, unas iban en la mañana y otras iban en la tarde. Sí fue cómo nosotros logramos romper que trabajábamos todo el día. Porque nosotros teníamos atención del almuerzo educativo.
Rosario Melgar de Varela: Nosotros ganábamos 300 colones por ir mañana y tarde, de lunes a sábado.

Consuelo Cabezas de Linqui: 50 colones era lo que nos daban de sobresueldo [risas].

Se doblan las escuelas experimentales. Es decir, hay turnos en la mañana y turnos en la tarde y eso se considera el primer paso para el fracaso, según Consuelo. ¿Pero qué pasó, por qué cierran las experimentales, las normales y las renovadas?

Consuelo Cabezas de Linqui: Cuando doblaron las escuelas, para mencionarle antecedentes, las escuelas experimentales eran como la guía porque en cada departamento había una o dos escuelas lo que en la universidad experimental se experimentaba, valga la redundancia, nosotros capacitábamos a los maestros de los departamentos.

$Y$ se aplicaba igual en los departamentos como en el Centro de San Salvador o de Santa Ana. Nosotros estábamos así con todos los maestros de la República, siguiendo una misma línea metodológica. Y nosotros dando las líneas dentro del ministerio. Por ejemplo ella -Rosariotrabajó enfocando la gran importancia que tiene la educación parvularia.

Conchita estaba trabajando en educación básica y yo en planificación para el maestro. Ahí con los maestros se hacía la planificación, la famosa currícula, eso se hacía con los maestros, no era lo que nosotros nos inventábamos. Y de acuerdo a las necesidades que ellos tenían. Y había una gran integración. Por ejemplo cada vez que íbamos a empezar el desarrollo de una unidad de 
trabajo o de un centro de interés nos reuníamos y planificamos el enfoque que se le iba a dar según los requerimientos de esas guías de trabajo. $\mathrm{Y}$ así planificamos. Y el padre de familia también estaba enterado. Porque le informábamos de tal fecha a tal fecha se va a ver tal unidad y para esto requerimos que usted contribuya en esto y esto.

Nosotras no éramos de las que dejábamos el montonazo para que al pobre padre de familia le toque hacer las tareas de los hijos. El aprendizaje se verificaba en el desarrollo cuando los niños estaban en el aula. Y claro, se les dejaba tarea. Pero no como ahora que es copie de tal página a tal página y sin ningún objetivo. Algo, como dicen, de las decisiones políticas cuando entró (Walter) Béneke, nosotros teníamos listos los nuevos programas con esa orientación. Pero Béneke tenía problemas políticos con los maestros y los maestros no aceptaron ni siquiera conocer los nuevos programas. $Y$ nos fuimos a la huelga. Porque con todo orgullo decimos: nosotras fuimos fundadoras de "ANDES 21 de Junio" porque veíamos el proceso educativo. Sobre eso luchamos, por mejorar la educación. No por políticos.

Rosario Melgar de Varela: Y fijese que las escuelas experimentales eran dos. Una en Santa Ana, la Tomás Medina, y la Romero Alvergue de aquí. Esas eran las claves.

Consuelo Cabezas de Linqui: Cuando hicieron un corte de que ya los sábados no trabajaban, no es que no trabajaban, el sábado lo hicieron porque decían los maestros: tenemos mucho trabajo, cuándo vamos a unificar, cuándo vamos a planificar porque trabajamos por ciclos. Todos los maestros que trabajaron en el primer ciclo, en el segundo ciclo y en el nivel básico que era antes, el tercer ciclo.
Entonces el sábado lo ocupábamos para planificar y ver de la planificación qué se está desarrollando qué problemitas había, qué enfoques no habían sido bien comprendidos. Pero lo hacíamos en equipos de maestros y teníamos un coordinador por cada sector. Ellos estaban pendientes de qué más necesitaba, perdonen que diga yo, pero estaban pendientes de qué más necesitaba para integrar el enfoque totalmente. Y siempre nos reforzábamos. Y siempre había participación. La participación era desde los alumnos chiquitos hasta los maestros. Todos estábamos bien integrados. Se puede lograr porque fijese que hay mucha conciencia en el maestro, todavía actualmente, y le digo por medio de los ensayos que están haciendo políticas estamos logrando que sí cambie. Por ejemplo, nosotras estamos involucradas ahí a pesar de que no pertenecemos a nada, pero sí, ellos desarrollan el proyecto y nosotros contribuimos más que todo a ir cambiando ese esquema mental del maestro. Sí se puede porque a los maestros si usted un día los oye va a ver qué necesidades tienen ellos de que cambie. Porque ellos son los primeros conscientes de que la educación en lugar de ir en avanzada va en retroceso. Son muy conscientes ellos.

Rosario Melgar de Varela: Es un desastre. Por eso es que muchos padres hacen el sacrificio de mandar a colegios privados a los hijos. Porque la escuela pública se ha deteriorado.

Consuelo habla de programas de cambios en los que ella ha colaborado actualmente. Ambas hablan de cómo se ha deteriorado la escuela pública, ¿Cuál es la imagen que ellas tienen de la educación pública actual?

Rosario Melgar de Varela: Mire, hay una pérdida de valores y además de eso las instituciones 
educativas han decaído, porque los señores que están en el Gobierno no tienen políticas claras para cada sector. Porque le digo, yo como maestra que he llegado a este nivel, me doy cuenta que las escuelas públicas dejan mucho qué desear. Los maestros están desmotivados y hay una anarquía.

Se lo digo porque yo vivo cerca de una escuela en Mejicanos. Entonces ahí no hay disciplina. Deja mucho que desear. Entonces no es que yo como una persona ya muy adulta diga que los tiempos anteriores fueron mejores, no, lo que pasa es que ahorita deberían de ser mejores. Pero la verdad es que vamos para atrás, hay mucho descuido. Entonces eso también viene desde arriba: Ministerio de Educación, que como que ha dejado una anarquía, cada quien hace lo que puede o lo que quiere. Pero es una anarquía que dan ganas de llorar a los que fuimos formados en aquella época, a los que estamos ya para morirnos [risas].

Pero dan ganas de decir: ya basta. Porque los maestros ahora no se comprometen, porque si usted llama la atención, viene la respuesta, y a veces desde los padres, y algunos alumnos hasta amenazan con esperar al maestro a la salida. $\mathrm{Y}$ lo que tenemos que hacer las instituciones educativas es revisar la currícula e insertar en ella aquellos elementos que contribuyan a sacar este caos que tenemos porque es un caos lo que tenemos en las escuelas. Esos niños ni siquiera salen formados. Ustedes no son de esa escuela pero nosotros nos criamos en salir formaditos, calladitos. Hoy esta cosa se acabó, hoy si es posible hasta insultan al maestro. Se les llama la atención y el padre de familia que tampoco colabora. Dejan a la escuela toda la actividad académica y la disciplina. Y entonces estamos en un caos. ¿Qué hemos logrado ahorita? Solo cuestiones negativas, muchachos malcriados.

Muchachos que ni saben qué quieren en la vida, no hay orientación vocacional. No hay disciplina. Los hogares también tienen la culpa porque los hogares muchas veces son permisivos y piensan que la escuela va a hacer todo. $\mathrm{Y}$ muchos maestros también que no colaboran. Ellos van por un salario y ya después que Dios los socorra.

Rosario Melgar de Varela: No, mire, hasta eso. La presentación de un maestro. El vestir. No se dice que llegue con lujos pero que lleguen correctamente vestidos. Pero ahora es un desastre. No todos, también hay que ser conscientes que no todos. Hace falta, aunque le han dado otros nombres lo de la supervisión, pero antes eran supervisores educativos. Ellos iban a revisar las planificaciones y los problemas que tenían los maestros pero hoy están como que son capataz, mala comparación, pero entonces no hay lo que debe ser un guía.

\section{Preguntamos a Rosario y Consuelo si todo esto tiene arreglo.}

Rosario Melgar de Varela: Tiene arreglo si todos los que estamos inmersos en esto planteamos algo al Ministerio de Educación. Podría ser bueno que nosotros tuviéramos acceso a esos estratos comunicacionales para que ellos entendieran lo que está sucediendo en las escuelas. Son pocas las escuelas que tienen esa mística profesional. Porque eso es lo que falta ahora, mística profesional. Pero el Ministerio de Educación da cursos, da la posibilidad de que las personas adquieran mejores condiciones para enseñar, metodologías y todo. Pero yo siento que 
no avanzamos, se requiere que haya gente más comprometida con la educación del país. Los directores y sus colaboradores tienen que tomar medidas. Y como docentes ellos tienen que hacer un diagnóstico, pero una cosa bien elaborada para ver qué es lo que está fallando. Desde cuándo venimos con esta falla. Que cada vez vamos de mal en peor. Ella es maestra también y hemos vivido la mismas cosas de ver cómo se ha ido deteriorando la educación porque ahora es un caos.

\section{¿Se puede revalorizar la profesión docente?}

Rosario Melgar de Varela: Mire, para revalorizarla tendríamos que hacer un plan, en primer lugar hacer un plan con el Ministerio de Educación y las instituciones educativas. Deberíamos estar integradas para que nosotros como entes secundarios (secundarios en el estrato organizativo) nosotros pudiéramos plantear qué es lo que la escuela necesita. Qué es lo que debe modificarse, recobrarlo, porque ahora ni siquiera disciplina.

Consuelo Cabezas de Linqui: Se puede, porque nosotros con las escuelas que hemos estado trabajando aún para tratar la violencia, para tratar la metodología que están dando, los nuevos enfoques de educación, hemos hecho ese experimento.

Que ellos sí han acogido y cómo nos han agradecido (aquella es una muestra, aquel diploma, muestra de cómo nosotras nos involucramos en enseñarles nuevos enfoques metodológicos). Claro nosotros los tratamos con los compañeros aquí de investigación. Pero ellos lo hacían extensivo y participábamos también nosotros. Por ejemplo ya en los grupos que han hecho investigación nos conocen porque hemos estado involucradas.

\section{¿Les parece que una solución sería refundar las Escuelas Normales?}

Rosario Melgar de Varela: Sí, sí porque la Escuela Normal era el centro de formación docente, ahí había desde cómo vestirse hasta todo lo que era la currícula y había disciplina y había orden. Pero el orden venía desde arriba, no era cuestión de que solo ellos se lo inventaban. Era cuestión que ya venía estipulado y la gente tenía que cumplir con eso. Y tener gente responsable para que supieran hacer lo que estaban haciendo pero poco a poco la educación ha ido decayendo, estamos como están los resultados.

\section{Roberto Salomón}

Las normalistas creen que el culpable del cierre de las Escuelas Normales fue Walter Béneke, el Ministro de Educación en el periodo 1967 - 1972 durante el Gobierno del General Sánchez Hernández. Béneke es una figura polarizante, y así como Consuelo y Rosario creen que es el culpable de una de las razones del declive de la educación en el pais, hay otras personas, como el siguiente entrevistado que creen que-algunas-de sus decisiones fueron acertadas.

Hablamos con el director artístico del Teatro Luis Poma: Roberto Salomón. Tiene más de 50 años de hacer teatro, ha dirigido más de 30 obras en E1 Salvador y Suiza y también ha dirigido en Estados Unidos y es la cara del teatro salvadoreño. 


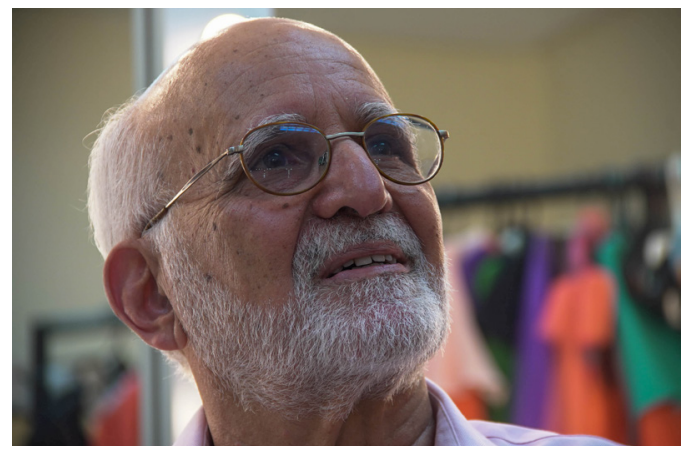

Imagen $n .^{\circ} 5$. Roberto Salomón, especialista en Educación Artística. Fotos: Raúl E. Benítez, periodista multimedia.

Con él hablamos sobre la educación artística, una de las tareas pendientes desde hace varios Gobiernos y que este ha tratado de rescatar vía el INFOD en los últimos meses.

La conversación con él se inicia en el meollo del asunto, la formación en artes en E1 Salvador... la falta de formación en artes en E1 Salvador.

Hay una cosa que es bien importante y es que en nuestro medio no hay formación sistemática de las artes. Digan lo que digan, lo que hacen la Matías, lo que hace el CENAR (Centro Nacional de Artes) no es una formación sistemática de las artes. Son clases, hay extensiones universitarias, yo defiendo totalmente el teatro universitario, me parece que es el semillero de los futuros artistas de El Salvador, mientras no haya educación sistemática y esto es muy importante, pero no hay educación sistemática. Nosotros hemos asumido, porque nadie nos ha pedido eso, nosotros hemos asumido en el teatro Luis Poma y en la fundación Poma hacer el trabajo que debería estar haciendo el Estado.
¿Qué le hace falta entonces a la universidad Matías Delgado o al CENAR para dar ese paso y que sí se considere como una formación sistemática?

Pues primero se necesita un currículum completo. Primero, antes que nada, se necesita lo que los Gobiernos no han tenido: es una voluntad política de crear carreras artísticas. Y si se van a crear carreras artísticas, ¿para qué se quiere crear un artista? $\mathrm{O}$ sea, ¿qué es lo que se quiere conseguir en una sociedad? $Y$ para eso hay toda una reflexión filosófica sobre la importancia del arte en la sociedad, que esta sociedad salvadoreña no la ha querido abordar, así de claro.

Fijate hay algo bien curioso, si vos revisás el programa de Lenguaje que está ahorita en uso, E1 Salvador debería casi que graduar o literatos o gente especializada en teatro.

$\mathrm{Y}$ estamos graduando gente que apenas sabe leer y escribir. Y que no saben, el 90 por ciento de los casos no saben redactar. Entonces por qué creés...

¡Pero porque no hay voluntad política! No hay una voluntad política en educación para cumplir con los planes de estudio, sencillamente.

En esos programas hay un apartado en la materia que es escenografía y técnico en luces de teatro...

¿De qué sirve hacer programas que no podés implementar? Si no hay personal para llevarlos a cabo. A mí me llamó el ministro de Educación, Carlos Canjura, que yo tenía mucha fe cuando él comenzó, dije: «esto va a ser formidable, me llamó para ver que hagamos un programa para enseñarles a profesores rurales a ser profesores de teatro. Y yo le digo: «¿Pero cómo vamos a hacer 
eso? Primeramente nunca les ha interesado el arte, ¿cómo vamos a hacer para interesarlos el arte? ¿En qué horarios se va a hacer esto? ¿Los sábados cuando tienen su día libre? ¿Por qué van a ir a una clase si no es obligatoria? Y si es obligatoria entonces no es bueno. ¿Por qué no se contrata a tanto artista capaz que hay en El Salvador? Porque tenemos un movimiento artístico, sobre todo el movimiento teatral, musical, de artes plásticas, de danza, todos los movimientos artísticos en El Salvador son excelentes. La gente nos admira en eso. ¿Por qué no contratar a personas que están sin trabajo y que tienen la capacidad para ir a hacerlo?». La respuesta fue: «Pero para eso no hay dinero».

\section{Esa respuesta creo que ha sido la constante en} todo esto.

Pero no es cierto que no hay dinero porque hay dinero cuando hay una voluntad política. Cuando hay una voluntad política se pueden hacer las cosas inclusive sin dinero. $\mathrm{O}$ sea, fue el caso del bachillerato en artes: había una voluntad política de un señor que se llamaba Walter Béneke, que quiso hacer una reforma educativa en el 68, que le cayó encima todo el movimiento magisterial, de manera muy fuerte, todo "ANDES 21 de Junio" le cayó encima y ahora el mismo FMLN está tomando esos programas que se hicieron para el bachillerato en artes y los están copiando y pegando. Cosa que se hace mucho en nuestro país en estos momentos, ¿¿verdad?

[Risas] Es muy chistoso porque en la entrevista que le hice a unas normalistas, ellas le echan la culpa a Béneke...Claro...de que por él se murieron cosas interesantes en la educación y ahora tu contraste es tan...

Sí, pero lo que es interesante de Walter Béneke es que era una persona con una dinámica muy fuerte. Entonces es cierto que arrasó con cosas que no debían haberse arrasado. Y una de ellas es la Escuela Normal. Pero acordémonos que Walter Béneke cerró Bellas Artes, que Bellas Artes tenía cinco años de no producir una obra, de no dar un concierto, de no crear exposiciones. Estaba la gente ahí totalmente anquilosada. Entonces el barrio con todo esto. Claro, cuando barrió la casa y una de esas cosas, yo estoy de acuerdo con las normalistas, fue la Escuela Normal. Si mi profesora que me enamoró del teatro fue la viceministra de él, que fue Antonia Portillo de Galindo [risas] que fue normalista.

Si de ti dependiera, Robby, entonces cuál sería el primer paso. Porque ahora creo que sabés que el ministerio, vía el INFOD, está tratando de hacer una contratación de maestros para implementar otra vez la enseñanza en artes en todas las escuelas del país.

¿Cómo lo van a hacer si no hay los fondos para hacerlo y no hay las personas capacitadas para dar esas clases? Entonces, ¿de qué sirve tener un programa si no hay una persona que pueda llevar a cabo ese programa? ¿Cómo hacés para formar a la gente? La tenés que empezar a formar desde la parvularia. Se quitan los programas de educación estética, se quitan los programas de apreciación artística, se quitan los programas de civismo. ¿Con qué se queda? Acordémonos que una sociedad se recuerda por sus artistas. Si te pregunto quién era el alcalde en Florencia o en Roma cuando se pintó la Capilla Sixtina no vas a saber quién era el alcalde, pero sí te vas a acordar de Miguel Ángel, el artista que la pintó. Esa es la cosa que no se dan cuenta, la importancia del arte. Entonces llega un ministro de la calidad de Carlos Canjura y no le dan los medios para hacer 
lo que él tiene en la cabeza de hacer, no le dan el seis por ciento del PIB, no le dan a Educación el dinero que merece. Entonces que no me digan que no hay dinero, porque para Defensa hay dinero. ¿Y de quién nos estamos defendiendo?

\section{De nosotros...}

Sí, pero es un problema interno ya [risas] y se supone que el Ejército defiende del exterior, ¿verdad? Entonces... Dijiste que no me quería hacer hablar de cosas [risas].

\section{¿Cuál tendría que ser el paso uno para enrumbar la educación artística?}

El paso uno es una voluntad política. Hay un pensamiento profundo en la derecha que el arte es un hobbie. $\mathrm{Y}$ hay un pensamiento profundo en la izquierda que el arte no sirve para nada. Mientras que esas dos cosas no se cambien en el país, no se puede adelantar, no se puede avanzar. Porque se necesita una voluntad política de entender, de estar convencido, así como estaba convencido Walter Béneke que la educación empieza en kínder, en la parvularia. Ahí es donde empieza la educación. Miren lo que pasó con la universidad. La universidad tenía profesores maravillosos en los años 60 que crearon gente maravillosa, pero esa gente maravillosa después se convirtió en profesores buenos, y esos profesores buenos después formaron gente buena, y esa gente buena se convirtió en profesores más o menos, y esas personas formaron gente más o menos, y esas gentes más o menos se convirtieron en profesores mediocres. Así se va. Es que sin una visión, como la visión que había para la universidad en los años 50 y 60, la visión que había para la cultura, para las artes. $\mathrm{O}$ sea, parece mentira que yo estoy defendiendo a un coronel que se llamaba Osorio que tuvo una visión de hacer una cosa cultural [risas]. No hizo solo los balnearios. Ahí tenemos el Monumento a La Revolución, "E1 Chulón”, que es una de los monumentos lindos que hay en El Salvador. Hay gente que le puede gustar o no gustarle, pero que es un monumento que es valioso, sí, lo es. ¿Verdad? Tenés la voluntad política.

\section{¿Paso dos?}

Paso dos, el personal. Yo sí creo firmemente que una de las razones por las que pudo funcionar el Centro Nacional de Artes y todo el programa del Bachillerato en Artes es porque tuvimos los medios de traer profesores extranjeros para que formaran a la gente. Vino gente capacitada de España, de Japón, de Estados Unidos, de Canadá, de Italia, de Francia. Vino gente de primer orden. Eh, de Rusia, en un Gobierno de derecha en los años 70 [risas]. Sí, son las contradicciones; sí, se dieron cosas muy buenas, pero... La voluntad política y luego la formación del personal. O sea, se traen profesores extranjeros formidables y se les pega como garrapata a un joven que quiere aprender y que es su asistente. Y esa persona está aprendiendo y después esta persona se tiene que ir becado al exterior, esa es la historia de Dinora Cañénguez. Si la UCA (Universidad Centroamericana José Simeón Cañas) tiene un programa de teatro, ¿por qué? Porque Dinora se le pegó a un profesor extranjero que vino hasta acá y luego se fue becada a España a estudiar y luego regresó. Es que no hay milagros.

Voluntad política, personal, más voluntad política. ¿Y después? Y dinero. 
¿La implementación? ¿Cómo creés que la harías? Mirá, te doy un ejemplo. A mí me llamaron para ser director del Isar (Instituto Superior de Artes), hace como cuatro meses, seis meses, no me acuerdo. Me llamaron hace también como 10 años. Yo dije que... [risas]. Pero hace unos meses, no recuerdo exactamente cuántos meses. Me llamaron para ser rector del Isar. En principio yo dije sí. Cualquier proyecto cultural, artístico que se puede desarrollar en El Salvador yo me apunto. Entonces, ¿qué es lo que pasó? Hay dos personas trabajando en el proyecto del Isar que han hecho un trabajo admirable, admirable, de fondo. O sea, tienen todos los programas, tienen todos los objetivos, tienen todo lo que necesitan las burocracias para creer en el proyecto. Ahí está. Está hecho. Me lo presentaron durante unos días, lo estuve viendo con ellos, hice mis preguntas, me pareció que estaba muy bien, bueno. Entonces yo puse dos condiciones. Una, se necesita un local. No es mucho pedir, ¿¿no? [risas]. Ese local debe ser un local simbólico y emblemático, entonces pedí el Palacio Nacional. De ahí: «No, no se puede». ¿Entonces qué? Para ir a alquilar un local que va a costar $\$ 3$ mil o $\$ 5$ mil o $\$ 10$ mil al mes en Santa Elena, que es una galera infeliz, por qué si el Palacio Nacional ahí está y no se está utilizando. ¿Por qué no se puede utilizar el Palacio Nacional para la cultura? Es un contrasentido. De ahí: «No hay dinero». Entonces, ¿qué voy a hacer siendo rector de una institución sin un local, sin dinero, con programas de estudio bastante bien elaborados, pero que no hay dinero para contratar gente ni hacer? ¿Entonces qué es lo que se va a hacer? ¿Se la va a mentir a la gente? Porque no puede ser de otro modo.
¿Pero cómo no puede haber dinero en el Isar? Si básicamente la continuidad de algo así depende del dinero.

Pues sí, ¿pero si no hay voluntad política? Yo en mi carta de renuncia, que no es una carta de renuncia porque no había firmado el contrato [risas], le dije a la ministra de Cultura: «Yo creo que tú quieres hacer el proyecto, pero si no te dan los medios a ti, no se puede hacer». Se creó el Ministerio de Cultura, el Ministerio de Cultura no tiene fondos. $\mathrm{O}$ los fondos que tiene son los mismos que tienen o tenía Concultura. Entonces, ¿para qué se creó el Ministerio de Cultura? Además se creó el Ministerio de Cultura al mismo tiempo que en Honduras lo estaban quitando. Cosa que es bien interesante a nivel simbólico, en cultura. El Ministerio de Cultura son los artistas los que estaban pidiendo en Honduras que se quitara [risas]. Se crea una Ley de Cultura, jen hora buena! Es una maravilla que tengamos una Ley de Cultura. ¿La están implementando? De qué sirve crear cosas si no las vamos a implementar. Estamos en llamarada de tusa, sin tusa [risas].

Vos decías que para la gente de derecha el arte es una hobbie y a la gente de izquierda probablemente no le importe. Qué creés...

No, no digo que a toda la gente. Yo digo que hay en ideología de derecha y de izquierda están esos dos extremos que finalmente se unen. A mí ya no me preguntan porque estoy muy viejo, pero a muchos artistas les preguntan: «Sí, pero aparte de arte, ¿qué hacés?». O sea, como si el arte no fuera un trabajo. Entonces, ¿cuál es la pregunta?

Esta gente, que no es todo, sino extractos entre la derecha e izquierda: ¿qué creés que es lo que no están viendo? ¿Y por qué a unos no les importa? Porque no les conviene. Porque reconocer que el arte es lo más importante en una sociedad 
es... Por supuesto, después de techo y comida, tampoco estoy abogando para que el arte sea más importante que la comida y el techo. Pero una vez que la supervivencia está lograda, lo más importante es el arte. Entonces, ¿qué es lo que hay que hacer? Hay que quitarlos [risas]. Yo creo que las cosas solos se pueden cambiar por educación.

\section{A manera de conclusión}

Dadas las voces escogidas en este artículo es posible determinar algunas similitudes $y$ diferencias entre sus discursos, pero más allá de eso es importante señalar que todos señalan que el Estado debe tener un papel más activo en la formación docente en El Salvador, esto requiere según los especialistas un nuevo marco legal que sustituya a la Ley de la Carrera Docente tal como la conocemos actualmente. Otro aspecto concluyente la necesaria revalorización de los y las docentes, pero este pasa por un auténtico acuerdo nacional que retome las experiencias acumuladas por el país en este tema en pro de resolver los problemas actuales: dignificación profesional docente, crecimiento profesional, pensiones, ingreso y permanencia a las carreras que habilitan para el ejercicio de la docencia, ingreso y permanencia en el sistema público de enseñanza y evaluación docente. 